\title{
Discrimination learning and extinction in toads'
}

\author{
PHILIP K. CHU and GARVIN McCAIN, University of Texas \\ at Arlington, Arlington, Texas 76010
}

Toads (Bufo woodhousii woodhousii and Bufo valliceps) were trained for position discrimination in a $T$ maze. One hundred-ninety acquisition trials were followed by 40 extinction trials. The curve obtained differed somewhat from the usual mammalian results. The Ss were performing at $60 \%$ correct response level at the end of the acquisition trials and extinguished very rapidly. The study also indicated species differences in adaptability to the lab situation.

The toad as a laboratory animal is seldom found in psychological experiments. Especially in the field of learning, there is a paucity of data on toads. A simple discrimination learning situation was chosen for the present experiment due to this lack of basic knowledge. In addition, there is a large amount of data available on other animals in such experiments, allowing at least rough comparisons. Brower \& Brower (1962) have reported that toads are capable of learning to discriminate noxious and nonnoxious food in very few trials. Williams (1967) tested toads in a T maze for dominance of cues, but his experiment utilized shock rather than food as a reinforcer. Since no other works on maze learning or other relatively difficult tasks using positive reinforcers on toads were available, the present study was considered as a pilot for future work. On this basis it was decided, in advance, that changes in procedures would be made as necessary.

\section{SUBJECTS AND APPARATUS}

Two species (10 Bufo woodhousii woodhousii and six Bufo valliceps) served as Ss. They were captured from ponds and streams around Arlington, Texas. All Ss were sexually mature (at least one year old) and were housed in 10-gallon "reptile" cages, three or four to a cage. Brown paper towels lined the floor of the cages and 8-in. diam aluminum pie plates served as water pans. Room temperature ranged from $76 \operatorname{deg} F$ to $84 \mathrm{deg} F$ with a mode of $80 \mathrm{deg} F$. Water and paper towels were changed frequently to maintain a clean habitat.

To feed the Ss, beatle larvae were kept alive in a large jar of wheat bran. Ss were fed ad lib until put on total deprivation for seven days preceding the acquisition trials. Identification of individual Ss was made possible by clipping $1 / 16$ in. off the tips of one or more toes. Of the six Bufo valliceps, two died and one was dropped for not eating. The valliceps adapted very poorly to the lab situation. They had a penchant for immobility and required far more prodding to get them to move. At the time they were dropped from the study (approximately 100 trials) all valliceps required prodding. It may be that valliceps are more difficult to train because of fear, or the lack of humidity control may have affected them since valliceps appear to require a higher level of humidity than do woodhousii.

A wooden T maze with two metal guillotine doors was used. Dimensions of the maze are given in Fig. 1. At the beginning of the study the right arm and guillotine door were painted black, the left arm and door white, and the start box grey. Six Ss were given a single trial in the maze to determine side preference. All Ss went to the white side. With the black side as the correct choice the Ss were run a total of 120 trials. In 98 out of these 120 trials, the white side was chosen (81.7\%). During this period the orientation of the maze was rotated 90 or $180 \mathrm{deg}$ daily. Because of this overwhelming preference for the white arm $(p<.01)$, the black-white discrimination situation was abandoned in favor of a position discrimination. Both arms then received a coat of white enamel paint.

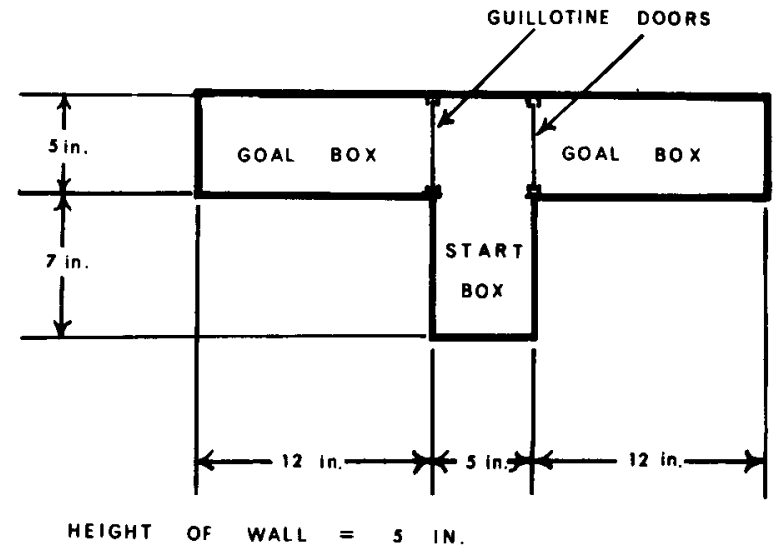

Fig. 1. Diagram of $\mathbf{T}$ mane.

\section{PROCEDURE}

The Ss were separated into groups of six, five, and five for convenience. Six coffee cans served as temporary receptacles during the experimental hours. Each member of each group was removed from its cage and placed in a coffee can at the beginning of the trial day and returned by hand to its cage at the end of the session. All Ss were given five spaced trials per day with an intertrial interval of roughly $20 \mathrm{~min}$. A total of 190 acquisition trials and $\mathbf{4 0}$ extinction trials were given. A noncorrection procedure was used on each trial. The $S$ was placed in the start box with both guillotine doors of the maze raised. When the $S$ entered an arm completely the guillotine door was immediately lowered converting the arm into a goal box. A correct choice was reinforced with a mealworm dropped immediately after the closing of the guillotine door.

During the first 30 trials, each $S$ was allowed up to $5 \mathrm{~min}$ in the start box before being prodded in the back to start him moving, and was left in the goal box for $5 \mathrm{~min}$. Throughout the rest of the experiment each $S$ was allowed $2 \mathrm{~min}$ in the start box, and was kept in the goal box for $1 \mathrm{~min}$. During extinction trials the same procedure was used - with the exception of omission of the reward. Instead, each $\mathbf{S}$ received three mealworms approximately $20 \mathrm{~min}$ after each daily session.

\section{RESULTS AND DISCUSSION}

Figure 2 consists of the data collected from the eight Bufo woodhousii woodhousii that finished the experiment. Each point on the graph represents a block of 20 trials.

As can be noted from Fig. 2, starting below chance level the acquisition function closely approximates a straight line

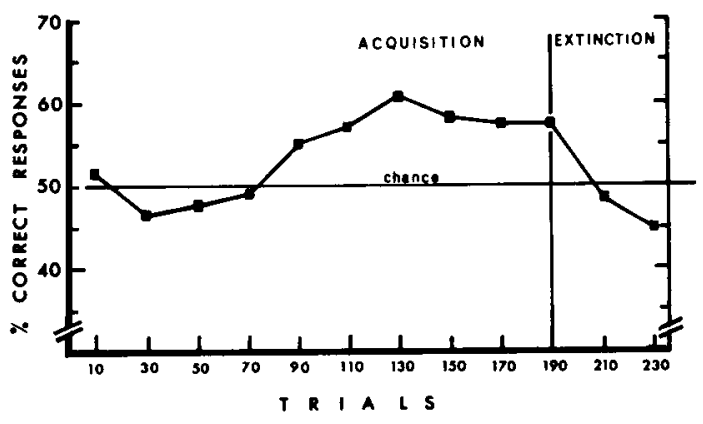

Fig. 2. Per cent correct responses in acquisition and extinction, plotted in blocks of 20 trials. 
reaching a plateau at the $58 \%$ correct response level around the 110th trial. Performance during the last 40 trials was significantly better than the first 40 trials $(t=2.69$, df $=7$, $\mathrm{p}<.05)$. The extinction function slopes sharply down to below chance level by the end of the first block of extinction trials. These results differ considerably from the usual rat discrimination learning curve in the lack of evidence of any negative acceleration.

Substantial individual differences in speed of learning as well as behavior was observed. Half of the Ss were quite tame by the end of the experiment. The other half still showed signs of fear when handled by the $E$. Two Ss reached the level of $75 \%$ correct responses around the 80 th trial, and two at about the 100th trial. The remaining Ss continued operating at chance level.

The results of the preliminary black-white discrimination situation was different from the study by Spigel \& Ellis (1965) who reported that frogs (Rana pipiens) preferred the black arm to either grey or white. It is clearly difficult to make meaningful comparison across species, as is shown by the difference in behaviors of even such closely related species as valliceps and woodhousii. The absence of even minimal data on most animals makes any serious comparative work sketchy at best.

\section{REFERENCES}

BROWER, L. P., \& BROWER, J. V. Z. Investigations into mimicry, Natural History, 1962, 71, 8-19.

SPIGEL, I. M., \& ELLIS, K. R. Brightness perference in the frog. Perceptual \& Motor Skills, 1965, 21, 367-370.

WILLIAMS, J. T., JR. A test for dominance of cues during maze learning by toads. Psychonomic Science, 1967, 9, 259-260.

$$
\text { NOTE }
$$

1. This experiment was supported by NSF Grant GY-4370 to the junior author. The authors express appreciation for the many helpful suggestions from William F. Pyburn, Professor of Biology, University of Texas at Arlington.

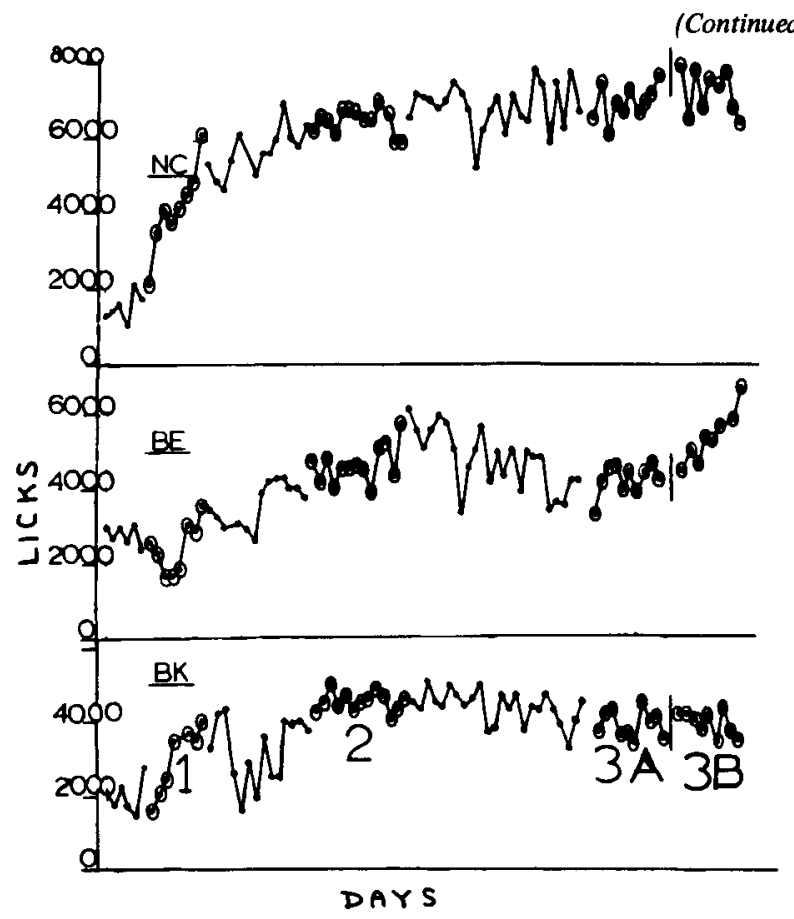

Fig. 2. Total daily water licks by each rat, without and with foot shock.

not increase above the the maximum of its new baseline, BK's increased to about 5000 licks, and BE's increased substantially, from a maximum in the immediately preceding baseline sessions of about 4200 licks to a new maximum of about 5800 . The baseline sessions that followed Series 2 showed still further elevations over previous baselines. Shock Series 3 had no significant effect in rats NC or BK, but elevated rat BE's licking still further, to a maximum on the last session of about 6300 licks. Although shock itself produced no marked effects in Rat NC in Series 2 and 3, there was a progressive rise in NC's drinking over the experiment, to a maximum close to 8000 licks in the last sessions.

The data suggest three conclusions. The first is that nonspecific emotional arousal by mild foot shock can enhance

\section{rom page 13)}

polydipsia. The second is that the enhancement remains or even increases after shock is discontinued. About $6000-8000$ licks probably represented an absolute maximum for this experiment. In the later sessions Rat NC was licking virtually all the time, except for very brief pauses to consume the pellets as they arrived. It could hardly have increased its licks further in the experimental time allotted, inasmuch as licking rate appears to be a constant in rats (Keehn \& Arnold, 1960; Schaeffer \& Premack, 1961). It may be that still further enhancement of polydipsia might have appeared, at least in Rat NC, had the experimental design permitted more time for licking.

The third conclusion is that at the mild shock intensities used, and even though shocks often arrived while the rats were actively drinking, the shocks had no effects on drinking that could clearly be described as punishing (unless the rise in drinking after shocks were discontinued be regarded as a delayed punishment effect-see Fig 11 in Azrin \& Holz, 1966, for a strikingly similar result in an experiment on punishment). Typically, when shocks came, the rats stopped drinking momentarily and then resumed. Having resumed, they continued drinking for longer periods than in the initial baseline sessions. This increase in duration of drinking persisted in subsequent baseline sessions, and accounts for the elevation in total licks per session.

\section{REFERENCES}

AZRIN, N. H., \& HOLZ, W. C. Punishment. In W. K. Honig (Ed.), Operant behavior: areas of research and application. New York: Appleton-Century-Crofts, 1966. Pp. 380-447.

FALK, J. L. Studies on schedule-induced polydipsia. In M. J. Wayner (Ed.), Thirst. New York: Pergamon Press, 1964. Pp. 95-116.

KEEHN, J. D., \& ARNOLD, E. M. M. Licking rates of albino rats. Science, $1960,132,739-741$.

SCHAEFFER, R. W., \& PREMACK, D. Licking rates in infant albino rats. Science, $1961,134,1980-1981$.

SEGAL, E. F., ODEN, D. L., \& DEADWYLER, S. A. Determinants of polydipsia: IV. Free-reinforcement schedules. Psychonomic Science, 1965a, 3, 11-12.

SEGAL, E. F., ODEN, D. L., \& DEADWYLER, S. A. Determinants of polydipsia: V. Effect of amphetamine and pentobarbital. Psychonomic Science, 1965b, 3, 33-34.

\section{NOTE}

1. These experiments were done at San Diego State College and supported by National Science Foundation Grants NSF GB 1605, NSF GB 5777, and NSF GB 7292. DLO ran the first experiment, and EFS ran the second with the assistance of David Brookshire and Michael Turner. 